\title{
Colite isquêmica
}

Pedro Duarte Gaburri

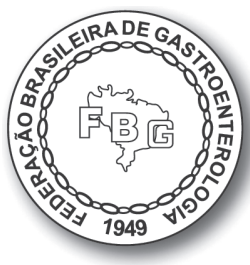

Júlio Maria Fonseca Chebli

Liliana Andrade Chebli

\section{CONCEITO E ETIOLOGIA}

A colite isquêmica (CI) é consequência de uma brusca e transitória redução do fluxo sanguíneo arterial do cólon em níveis abaixo daqueles necessários para satisfazer suas necessidades metabólicas, levando a inflamação, ulcerações e hemorragia, cuja gravidade resultará da duração e da intensidade da baixa perfusão, podendo variar desde lesões superficiais de mucosa e submucosa até necrose completa de toda a parede do cólon. Sua origem é, frequentemente, multifatorial, e a existência de múltiplas comorbidades aumenta seu risco ${ }^{1}$. Relevante destacar que a CI e a isquemia mesentérica são condições distintas, embora confundidas com frequência, como se fossem a mesma doença com localizações diferentes. A CI é uma condição aguda e pode ocorrer em qualquer segmento do cólon, mas o descendente e o sigmoide são as áreas mais afetadas. Em uma revisão de 250 casos, o sítio das lesões ocorreu em 12\% no cólon direito, $17 \%$ no transverso e flexura esplênica, $11 \%$ na flexura esplênica apenas, $20 \%$ no descendente ou $20 \%$ no sigmoide, $14 \%$ desde a flexura esplênica o sigmoide, e apenas $6 \%$ no reto ${ }^{2}$. A isquemia pode ser causada por mecanismos oclusivos ou não oclusivos da luz arterial, estas últimas decorrentes de vasoespasmo ou queda acentuada do volume sanguíneo, como no choque hipovolêmico. $\mathrm{O}$ dano à mucosa se faz não só pela isquemia, mas também pela reperfusão que se segue ao espasmo vascular. As formas mais graves apresentam elevado índice de mortalidade e requerem assistência multidisciplinar de gastroenterologistas e cirurgiões, embora a abordagem conservadora possa, frequentemente, conduzir à sua resolução ${ }^{1}$. As causas mais comuns da CI, agrupadas em fisiológicas ou iatrogênicas, encontram-se demonstradas na Tabela 1. 
Tabela 1 Principais causas de colite isquêmica

\begin{tabular}{lll}
\hline Fisiológicas & Sistêmica & $\begin{array}{l}\text { Insuficiência cardíaca congestiva, síndrome da } \\
\text { resposta inflamatória sistêmica, aterosclerose }\end{array}$ \\
\cline { 2 - 3 } & Embólica & Fibrilação atrial \\
\cline { 2 - 3 } latrogênicas & Frombótica & Neoplasias e doenças hematológicas concomitantes ${ }^{3}$ \\
\hline Cirúrgica & $\begin{array}{l}\text { Quimioterapia, hormônios sexuais, terapia com } \\
\text { interferon, pseudoefedrina, glicosídeos cardíacos, } \\
\text { diuréticos, estatinas, anti-inflamatórios não } \\
\text { hormonais, imunossupressores, vasopressores }\end{array}$ \\
\hline Endoscópica & Tratamento de aneurisma da aorta abdominal \\
\hline
\end{tabular}

Fonte: adaptada de Trotter, Hunt e Peter, 2016

A CI é a forma mais comum de isquemia gastrintestinal, podendo ser confundida com isquemia mesentérica aguda, doenças inflamatórias intestinais (DII) e colites infecciosas ${ }^{8}$. Na CI, as lesões podem ser apenas superficiais e restritas à mucosa e à submucosa nos casos em que o baixo fluxo é mais suave e de mais curta duração, porém podem ser profundas, atingindo toda a espessura da parede do cólon em casos mais graves ${ }^{9}$. Na maioria das vezes, a CI é decorrente de uma isquemia não oclusiva que leva a uma brusca redução no fluxo sanguíneo pelas pequenas arteríolas da parede colônica resultante de uma queda do volume sanguíneo ${ }^{10,11}$. Os fatores associados com episódios mais graves de mau prognóstico e que podem não ter resolução com medidas conservadoras, necessitando tratamento cirúrgico, incluem comprometimento do cólon direito, sexo masculino, ausência de sangramento retal, insuficiência renal, estreitamentos da luz do cólon e peritonite ${ }^{6,12}$.

\section{APRESENTAÇÃO CLÍNICA}

Os sintomas são de apresentação aguda, e os mais comuns são diarreia, hematoquezia e dor abdominal em cólica ${ }^{13}$. Ao exame físico, o abdome é flácido com sensibilidade dolorosa sobre o segmento do cólon afetado. A presença de peritonite sugere isquemia mais grave, perfuração ou a possibilidade de outra causa para o quadro agudo que não a CI. O início agudo do quadro é um útil indicador diferencial com as colites inflamatórias e infecciosas, as quais têm início mais insidioso ${ }^{14}$. Os sintomas da CI se manifestam em horas e podem se acentuar com instabilidade sistêmica podendo levar a taquicardia, hipotensão, taquipneia e, ocasionalmente, febre sem foco infeccioso. Um quadro de choque levando à falência de múltiplos órgãos pode ocorrer se o tratamento adequado não for instituído. 


\section{ALTERAÇÕES LABORATORIAIS}

$\mathrm{Na}$ presença de hematoquezia, recomenda-se o estudo dos testes de coagulação sanguínea, inclusive a pesquisa de causas de trombofilia e dos níveis séricos de hemoglobina ${ }^{1}$. Leucocitose com neutrofilia e elevação da proteína C-reativa (PCR) podem estar presentes como marcadores inflamatórios. A função renal deve ser avaliada pela possibilidade de ocorrência de síndrome de resposta inflamatória sistêmica (SIRS) e suas consequências sobre os órgãos vitais.

\section{DIAGNÓSTICO}

Os pacientes precisam de atendimento de urgência. A tomografia computadorizada (TC) deve ser o procedimento diagnóstico inicial, podendo revelar espessamento da parede do cólon e anormal ou ausente reforço pelo meio de contraste, ingurgitamento venoso e presença de gases na parede intestinal (pneumatose intestinal) em casos mais graves ou avançados. $\mathrm{O}$ achado de líquido livre na cavidade abdominal ou de gás na veia porta também pode estar presente nas formas mais graves.

A colonoscopia é o método ideal para a confirmação diagnóstica, devendo ser realizada dentro de 48 horas para visualizar a mucosa e a intensidade das lesões ${ }^{6}$. Os dados indicadores de CI não gangrenosa incluem a presença de hemorragias petequiais, fragilidade e edema da mucosa, eritema segmentar, erosões esparsas, ulcerações longitudinais e uma delimitação marcante do segmento afetado com aquele do cólon normal. O encontro de cianose e pseudopólipos sugere isquemia transmural. Estudo retrospectivo de 659 casos de CI não registrou nenhum episódio de perfuração intestinal com o emprego da colonoscopia, demonstrando a sua segurança no diagnóstico.

\section{TRATAMENTO}

As medidas iniciais a serem adotadas no tratamento da CI incluem hidratação venosa e avaliação do balanço hídrico e acidobásico pela gasometria arterial, o controle da glicemia e seu monitoramento em diabéticos, havendo necessidade de cuidados intensivos de ressuscitação em casos de SIRS, os quais têm grande valor sobre o prognóstico da doença. Com as medidas citadas, a inflamação colônica e os sintomas a ela relacionados podem regredir sem necessidade de abordagem cirúrgica. Esta última deve ser empregada em casos de perfuração, peritonite generalizada ou hemorragia persistente conduzindo à instabilidade hemodinâmica e à necessidade de repetidas transfusões sanguíneas. 
Os doentes devem ser mantidos sem alimentação oral, pela possibilidade de evolução para tratamento cirúrgico. Na presença dos fatores já previamente citados, que indicam episódios mais graves, e em casos de piora da evolução clínica, deve-se considerar a repetição da TC e a indicação de abordagem cirúrgica do caso. Os pacientes que requerem tratamento cirúrgico têm uma mortalidade mais elevada, que pode chegar a $48 \%{ }^{1}$. A ressecção segmentar com colostomia representa a conduta cirúrgica mais adotada nestes casos. Anticoagulação terapêutica não é indicada, mas seu uso é recomendado profilaticamente nos pacientes com fatores de risco para CI. Destaque-se que $43 \%$ dos pacientes com CI têm sido identificados com êmbolos de origem cardíaca ${ }^{1}$. A última diretriz sobre CI do American College of Gastroenterology recomenda o uso de antibióticos, embora haja fraca evidência do benefício de seu emprego ${ }^{6}$.

Após a resolução do quadro, levando-se em conta que a CI é uma doença de origem multifatorial e associada a diversas comorbidades, torna-se imperativo abolir o uso de tabaco, reduzir a ingestão alcoólica e intensificar as atividades físicas. Não existem evidências de benefício no uso de antiagregantes plaquetários, por não se tratar de uma entidade exclusivamente aterosclerótica. Caso medicações cardiológicas tenham sido interrompidas durante a crise aguda da doença, vale destacar que sua reintrodução deve ser cautelosa, a fim de evitar riscos de hipotensão arterial e, que pode exacerbar a isquemia colônica. Os doentes que necessitam de tratamento cirúrgico têm prognóstico mais grave.

\section{ACOMPANHAMENTO CLÍNICO}

Na ausência de complicações da CI, após a alta hospitalar, a equipe médica que cuidará do paciente deve estar atenta para o fato de que há possibilidade de recorrência em 6,8 a $16 \%$ dos casos $^{6}$. Estenose do cólon pode ocorrer no local da isquemia, ocasionando constipação, flatulência, cólicas e anemia secundária à perda crônica de sangue pelas fezes, oriunda de uma úlcera crônica residual.

\section{REFERÊNCIAS BIBLIOGRÁFICAS}

1. Trotter JM, Hunt L, Peter MB. Ischaemic colitis. BMJ. 2016;355:i6600.

2. Brandt LJ, Boley SJ. Colonic ischemia. Surg Clin North Am. 1992;72(1):203-29.

3. Hass DJ, Kozuch P, Brandt LJ. Pharmacologically mediated colon ischemia. Am J Gastroenterol. 2007;102:1765-80.

4. Bielefeldt K. Ischemic colitis as a complication of medication use: an analysis of the Federal Adverse Event Reporting System. Dig Dis Sci. 2016;61:2655-65.

5. Perry RJ, Martin MJ, Eckert MJ, Sohn VY, Steele SR. Colonic ischemia complicating open vs endovascular abdominal aortic aneurysm repair. J Vasc Surg. 2008;48:272-7. 
6. Brandt LJ, Feuerstadt P, Longstreth GF, Boley SJ. American College of Gastroenterology. ACG clinical guideline: epidemiology, risk factors, patterns of presentation, diagnosis, and management of colon ischemia (CI). Am J Gastroenterol. 2015;110:18-44, quiz 45.

7. Da Silva E. Ischemic colitis after a routine colonoscopy: report of two cases. Am J Gastroenterol. 2014;109(Suppl 2):S397.

8. Nikolic AL, Keck JO. Ischaemic colitis: uncertainty in diagnosis, pathophysiology and management. ANZ J Surg. 2018;88(4):278-83.

9. Fitzgerald JF, Hernandez LO III. Ischemic colitis. Clin Colon Rectal Surg. 2015;28:93-8.

10. Brandt IJ, Boley SJ, Goldberg I, Mitsudo S, Berman A. Colitis in the elderly. A reappraisal. Am J Gastroenterol. 1981;76:239-45.

11. Brandt IJ, Feuerstadt P, Blaszka MC. Anatomic patterns, patient characteristics, and clinical outcomes in ischemic colitis: a study of 313 cases supported by histology. Am J Gastroenterol. 2010;5:2245-52.

12. O’Neill S, Elder K, Harrison SJ, Yalamarthi S. Predictors of severity in ischaemic colitis. Int J Colorectal Dis. 2012;27:187-91.

13. Mosele M, Cardin F, Inelmen EM, Coin A, Perissinotto E, Sergi G, et al. Ischemic colitis in the elderly: predictors of the disease and prognostic factors to negative outcome. Scand J Gastroenterol. 2010;45(4):428-33.

14. Sawczenko A, Sandhu BK. Presenting features of inflammatory bowel disease in Great Britain and Ireland. Arch Dis Child. 2003;88:995-1000. 